\title{
$\begin{array}{ll}\text { Research Square } & \text { Preprints are preliminary reports that have not undergone peer review. } \\ \text { They should not be considered conclusive, used to inform clinical practice, }\end{array}$ or referenced by the media as validated information. \\ Berbamine Inhibits Cell Proliferation, Migration, and Invasion and Induces Cell Apoptosis of A549 Cells Via Regulating C-Maf, PI3K/Akt and MDM2-P53 Pathways
}

Lili Liu

The Affiliated Zhangjiagang Hospital of Soochow University

\section{Zhiying Xu}

The Affilated Zhangjiagang Hospital of Soochow University

\section{Binbin Yu}

The Affiliated Zhangjiagang Hospital of Soochow University

\section{Li Tao}

The Affiliated Zhangjiagang Hospital of Soochow University

Ying Cao ( $\nabla$ caoyaoshi@126.com)

The Affiliated Zhangjiagang Hospital of Soochow University https://orcid.org/0000-0002-2850-808X

\section{Research}

Keywords: Berbamine, A549, apoptosis, PI3K, MDM2, c-Maf

Posted Date: October 16th, 2020

DOI: https://doi.org/10.21203/rs.3.rs-90754/v1

License: (c) (i) This work is licensed under a Creative Commons Attribution 4.0 International License.

Read Full License 


\section{Abstract}

\section{Background}

To investigate the influences of berbamine (BBM) on the cell viability, proliferation, and migration of A549 cells in vitro and in vivo, and explore the possible mechanisms.

\section{Methods}

After the A549 cells were treated with BBM, the cell viability and proliferation of the cancer cells were detected by MTT assay, EdU assay, and colony formation assay. Migration and invasion of cancer cells were illustrated through wound scratch assay and transwell assay. Apoptosis of cancer cells was evaluated by trypan blue dye exclusion assay and elisa assay. Beside, the expression of PI3K/Akt signal pathway-related proteins and c-Maf were detected employing western blotting assay. Xenografted model of NSCLC was used to detect the effect of BBM on tumor growth and metastasis in vivo.

\section{Results}

MTT assay showed that BBM inhibited the viability of A549 cells in a concentration-dependent manner and time-dependent manner. The results from the colony formation assay and EdU assay revealed that BBM $(10 \mu \mathrm{M})$ could significantly inhibit the proliferation of A549 cells $(P \& 0.001)$. And BBM $(10 \mu \mathrm{M})$

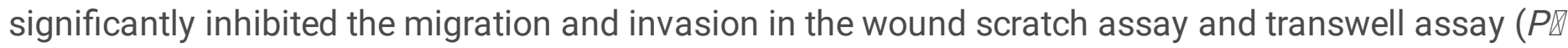
0.05). Trypan blue assay and elisa assay indicated that BBM $(20 \mu \mathrm{M})$ significantly induced apoptosis of A549 cells. The nude mice assay manifested the tumor volume was significantly shrank by BBM (20 $\mathrm{mg} / \mathrm{kg})(P ख 0.05)$. Western blotting assay showed that the PI3K/Akt and MDM2-p53 signaling pathways were inhibited by BBM, and the expression of c-Maf was downregulated by BBM.

\section{Conclusions}

BBM could inhibit the proliferation and metastasis, and induce apoptosis of A549 cells in vitro and in vivo, these effects may be achieved by reducing the expression of c-Maf and regulating the PI3K/Akt and MDM2-p53 pathways.

\section{Background}

Lung cancer is the leading cause of cancer-related death in both men and women around the world. The incidence of lung cancer in China was 73.3 per 100,000, ranking the first among malignant tumors and is the leading cause of death from cancer in both males (27.21\%) and females (21.92\%)[1]. Non-small-cell lung cancer (NSCLC) accounts for approximately $85 \%$ of all lung cancers, and usually diagnosed at an advanced stage with metastasis[2]. Treatments for patients with advanced cancer almost have little therapeutic effect. And relapse often follows the therapy, which highlights the massive need for new strategies. 
The Chinese medicine always provides a hopeful strategy for patients with advanced tumors. Berbamine (BBM) is derived from a traditional Chinese medicine of Berberis amnrensis Rupr, it has been widely used in Asian countries for patients with leukopenia that caused by chemotherapy and/or radiotherapy without any obvious side effects[3]. It has been reported to possess the effects of anti-oxidation, immunoregulation, and anti-arrhythmia in recent studies[4-7]. BBM was also revealed to have potential function of antitumor[8-10]. However, there were few studies on the anti-tumor effect of BBM in lung cancer,and the in vitro studies just evaluated the cell activity and migration, and the mechanism involved was just $\mathrm{Bcl}-2 / \mathrm{Bax}$. Moreover, the in vivo experiment only involved the tumor size and animal weight. Thus, more tests are needed to study the mechanism of BBM on NSCLC.

The abnormality of PI3K/Akt signaling pathway is related with tumor progression. Activation of PI3K/Akt signaling pathway existed in a wide range of human tumor spectra[2]. Studies showed that lung cancer's metastasis and drug resistance are closely related with PI3K/AKt signaling pathway[11-13], and it is mainly due to the amplification of PI3K or the overaction of Akt or the mutation of some regulatory components in this pathway[14]. Thus, a well understanding of the PI3K/Akt signaling pathway is helpful to find potential targets for lung cancer. MDM2 is a novel downstream gene of PI3K. Elevated MDM2 levels promote ubiquitination and degradation of E-cadherin, which in turn promotes cancer cell invasion[15]. PI3K/Akt and MDM2-p53 are crucial pathways in regulating cell activity. C-Maf is a member of the basic leucine zipper transcription factors[16], it was reported to potently active on the expression of IL-4 and IL-10. In breast cancer cell lines of MDA-MB-231 and MCF, the c-Maf is high expressed[15].

This study will investigate the effect of BMM on lung cancer in vitro and in vivo. The in vitro study will discuss the effect of BBM on cell viability, proliferation, invasion and migration in A549 cells, and indirectly explore the effect of BBM on cell cycle. The in vivo study will detect the effect of BBM on tumor growth and metastasis in nude mice. Besides, the expression of c-Maf and proteins in PI3K/Akt pathway will be detected through western blotting assay.

With the characteristics of low toxicity, exploiting BBM either alone or in combination with other chemotherapy may provide a new treatment strategy for lung cancer.

\section{Reagents And Methods}

\section{Reagents}

Berbamine dihydrochloride (BBM, purity $\geq 98 \%$ ) was purchased from Macklin (Shanghai China). PRMI 1640 Medium and Fetal Bovine Serum (FBS) were provided by Gibco (America). Matrigel was obtained from BD Biosciences (America). Cell Death Detection Elisa and 3-(4, 5-dimethylthiazol-2-yl)-2, 5-diphenyl tetrazolium bromide (MTT) were supplied by Sigma (America). The antibodies of PI3K, MDM2, Akt, p-Akt, p53 and GAPDH were purchased from Abcam (England), Bcl-2, Bax and c-Maf were purchased from Santa Cruz Biotechnology (America), caspase-3 and $\beta$-actin were purchased from Proteintech (America). All the other reagents were got from Beyotime Biotechnology (Shanghai, China). 


\section{Cell line and cell culture}

The human NSCLC cell line A549 was obtained from the Cell Bank of the Chinese Academy of Sciences (Shanghai, China). The cells were cultured with RPMI 1640 medium containing 10\% FBS in a humidified atmosphere with $5 \% \mathrm{CO}_{2}$ at $37^{\circ} \mathrm{C}$. The final DMSO concentration was less than $0.1 \%$ throughout all the study.

\section{MTT assay}

Cell viability was detected by MTT assay. Briefly, A549 cells were cultured in 96 -well plates $\left(1 \times 10^{4}\right.$ cells/well), treated with vehicle or BBM $(0,1.25,2.5,5,10,20,40$ and $80 \mu M)$ for $24 \mathrm{~h}, 48 \mathrm{~h}$ and $72 \mathrm{~h}$. Then the MTT solution $(5 \mathrm{mg} / \mathrm{ml})$ was added to each well and cultured for $4 \mathrm{~h}$. Finally, the supernatant was gently removed and $200 \mu$ DMSO was added to each well, the absorbance was detected by a Multiwell Microplate Reader (Bio-Rad Laboratories) at $560 \mathrm{~nm}$.

\section{Colony formation assay}

A549 cells were inoculated into 6-well plates and treated with vehicle or different concentrations of BBM $(10,20$ and $40 \mu \mathrm{M})$ for $24 \mathrm{~h}$. Then the medium was gently replaced with complete medium (with $10 \%$ FBS) and the medium was replaced every 3 days. The cells were stained with crystal violet after incubating for 8 days. The colonies were counted.

\section{EdU cell proliferation assay}

A549 cell proliferation was evaluated by Edu Apollo-567 In Vitro Kit (Ribo Bio, Guangzhou, China). EdU is a thymine nucleoside analogue, which can replace thymine and insert into the DNA molecule that is replicating during the cell cycle. The activity of DNA replication could be quickly detected by the Apollo fluorescent dye. In Brief, A549 cells $\left(8 \times 10^{3}\right.$ cells/well) were planted into 96-well plates with vehicle and $\operatorname{BBM}(10,20$ and $40 \mu \mathrm{M})$ and cultured for $24 \mathrm{~h}$. EdU was added and incubated for $2 \mathrm{~h}$. Cell nuclei were stained with Hoechst 33342 for 30 min. Finally, the cells were observed via an inverted fluorescence microscope (Leica, Germany). Five views with at least 500 cells were randomly selected for EdU ratio assay (EdU/Hoechst 33342).

\section{Trypan Blue Dye exclusion assay}

A549 cells $\left(8 \times 10^{4}\right.$ cells/well) were inoculated into the 6-well plate and treated with vehicle or different concentrations (10,20 and $40 \mu \mathrm{M})$ of BBM respectively. The cells were treated for $48 \mathrm{~h}$. Then trypan blue staining was performed and the cells were photographed within 5 min. At least 500 cells were seen in each view.

\section{Apoptosis assay}


Apoptosis was detected by Cell Death Detection Elisa Kit. This assay is based on the quantitative sandwich immunoassay using antibodies against histones and DNA. Thus the detection of mono- and oligo-nucleosomes in the cell lysates can indirectly represent the apoptosis of cells. A549 cells were seeded into the six well plates and cultured with or without different concentrations of BBM for $24 \mathrm{~h}$. Then the cells were washed with ice-cold PBS. RIPA lysis buffer (with $1 \mathrm{mM} \mathrm{PMSF}$ ) was added to the well and the supernatant was used for testing. The mono- and oligo-nucleosomal fragmented DNA was measured by a Multiwell Microplate Reader.

\section{Wound scratch assay}

A549 cells were seeded into the 6 -well plate $24 \mathrm{~h}$ before scratching. A $200 \mu \mathrm{l}$ plastic tip was used to generate a straight line. Fresh serum-free medium with vehicle or different concentrations $(10,20$ and 40 $\mu \mathrm{M})$ of BBM were added to each well. The cells were imaged at $0 \mathrm{~h}$ and $24 \mathrm{~h}$ in the same position of the wound. The migration distance was measured by $\mathrm{NIH} \mathrm{Imaje} \mathrm{J}$ software. Mitomycin $(2 \mu \mathrm{g} / \mathrm{ml})$ was always added to exclude the proliferation of the cells.

\section{Transwell assay}

Transwell assay was performed to evaluate the effect of BBM on the migration (without Matrigel) and invasion (with Matrigel) ability of A549 cells. Briefly, cells ( $4 \times 10^{4}$ cells/well) were seeded into the upper chamber of the $8 \mu \mathrm{m}$ pore (Corning, America) in serum-free medium, the lower chambers were added with full medium (with 10\% FBS). The cells were allowed to invasion and metastasis through the chambers at $37^{\circ} \mathrm{C}$ for $24 \mathrm{~h}$. Then the cells invaded to the surface of the lower chambers were stained. The number of cells passing through the chambers represents the metastasis ability of the cells. Mitomycin $(2 \mu \mathrm{g} / \mathrm{ml})$ was always added to exclude the proliferation of the cells.

\section{Experimental animals}

Male BALB/c nude mice (6 weeks old, weighing 18-20 g) were obtained from GemPharmatech Co., Ltd (Jiangsu, China). The mice were housed in polystyrene, well aerated cages with 12-h light/dark cycle. The animals were maintained on a standard pelleted diet and were provided with free access to food and water adlibitum. All studies were performed with the approval of ARRIVE Guidelines (Animal Research: Reporting of in Vivo Experiments) and approved by the Animal Care and Use Committee of Soochow University.

\section{In vivo assay}

Nude mice were transplanted to the right axillary of the nude mice. When the tumor volume $(\mathrm{W} 2 * \mathrm{~L} / 2, \mathrm{~W}=$ wide, $\mathrm{L}=$ long) reached to $150 \mathrm{~mm}^{3}$, the mice were randomly divided into 3 groups, the control group (Ctrl) and the experimental group ( $20 \mathrm{mg} / \mathrm{kg}$ and $40 \mathrm{mg} / \mathrm{kg}$ ). Each group had 6 mice. The mice were treated intraperitoneally with saline and different concentrations of BBM for 10 days. The body weight and tumor volume of the mice were recorded every 6 days. At the end of the experiment, the mice were 
sacrificed and the tumors were prepared for western blotting assay. The weight and the metastatic nodules of lungs were recorded. And the visceral tissues were sliced for histopathological examination.

\section{Histopathological studies}

To study the histopathological change of various organs, Hematoxylin/Eosin Staining kit (Beyotime, China) was employed. The tissues were fixed and sectioned at 3-4 $\mu \mathrm{m}$. Then the slices were stained with the Hematoxylin/Eosin Staining kit according to the reagent instruction. Histopathological scrutiny was observed by the microscope (Leica, Germany).

\section{Western blotting assay}

For protein analysis of PI3K/Akt and MDM2-p53 signal pathways, PI3K, p-Akt, Akt, MDM2, p53, c-Maf, caspase-3, Bcl-2 and BAX were detected. The harvested cells or tumors were lysed with RIPA lysis buffer (containing $1 \mathrm{mM}$ PMSF). The protein samples were separated on $10 \%$ SDS-PAGE and transferred to PVDF membranes. The membranes were blocked in $5 \%$ skim milk for $2 \mathrm{~h}$, then probed with primary antibodies of PI3K, Akt, p-Akt, MDM2, p53, c-Maf, Bcl-2, BAX, caspase-3, $\beta$-actin, and GAPDH at $4{ }^{\circ} \mathrm{C}$, followed by secondary antibodies at room temperature. The immunoreactive complexes were detected by Enhanced ECL Chemiluminescence Detection Kit (Beyotime, China). Relative optical density (ratio to GAPDH) was quantified by NIH Image J software.

\section{Statistical analysis}

The data were presented as mean \pm standard deviation (SD). The statistics were analyzed using SPSS software (SPSS 21.0, CA). Statistical differences were evaluated by Student's t-test or one-way ANOVA method, the accepted level of significance was $P \otimes 0.05$.

\section{Results}

\section{BBM was intensely cytotoxic to A549 cells}

The in vitro cytotoxicity of BBM was evaluated by MTT assay, colony formation assay and EdU assay. BBM effectively inhibited the growth of $A 549$ cells in a time ( $24 \mathrm{~h}, 48 \mathrm{~h}$ and $72 \mathrm{~h})$ - and dose $(0,1.25,2.5$, $5,10,20,40$ and $80 \mu \mathrm{M})$-dependent manner. A significant viability reduction was detected the concentration of $10 \mu \mathrm{M}(P<0.01$, Figure.1 A). The IC50 values of BBM against A549 cells were $8.3 \pm 1.3$ $\mu \mathrm{M}$ in $72 \mathrm{~h}$ - treated condition (Figure.1 B). Moreover, the colony numbers were significantly decreased compared to the control group ( $P<0.001$, Figure. $1 \mathrm{C}$ and $\mathrm{D})$, amounting to $72.6 \% \pm 1.2 \%$ reduction of cell proliferation was detected at the dose of $10 \mu \mathrm{M}$. Antiproliferative effect of BBM on A549 cells was also validated through EdU assay. As shown in the results, BBM caused concentration-dependent reduction of proliferation in A549 cells (Figure.1 E and F). At the dose of $10 \mu \mathrm{M}$, BBM led to a decrease $(58.7 \% \pm 2.6$ $\%)$ of EdU positive cells compared to the Ctrl group $(P<0.001)$. Collectively, these results indicated that BBM could inhibit the proliferation of A549 cells. 


\section{BBM induced apoptosis of A549 cells}

Trypan Blue Dye exclusion assay and Cell Death Detection Elisa Kit were used to test the apoptosis effect of BBM on A549 cells. Results showed that BBM induced cell death in a dose-dependent manner, and significantly increased the percentage of trypan blue-positive A549 cells at the dose of $10 \mu \mathrm{M}(P<0.001$, Figure.2 A and B). Results were further confirmed by an Elisa assay that quantifies mono- and oligonucleosomal fragments of DNA in the cell cytoplasm. As it turned out, BBM $(20 \mu \mathrm{M})$ significantly increased the death of $A 549$ cells, and the apoptosis ratio was $20.1 \% \pm 4.3 \%$ more than the control group $(P<0.05$, Figure.2 C). These results confirmed that BBM could induce apoptosis of A549 cells.

\section{BBM inhibited migration and invasion of A549 cells in vitro}

Migration and invasion are the main reasons of morbidity for the patients with cancer. The effects of BBM on migration and invasion of A549 cells were tested by wound scratch assay and transwell assay. The results from scratch woundhealing test indicated that BBM inhibited wound closure in a dose dependent manner (Figure. $3 \mathrm{~A}$ and $\mathrm{B}$ ). The statistical results showed that BBM significantly inhibited the migration of $A 549$ cells, and the healing area was $28 \% \pm 5 \%$ less than the Ctrl group at the concentration of $10 \mu \mathrm{M}(P<0.05)$. To further demonstrate the results, transwell assay was employed. Counting the number of cells on the surface of the lower chambers, we found that BBM significantly inhibited the migration and invasion of A549 cells in a dose-dependent manner (Figure.3 C - E). In the transwell assay (without matrigel), the number of cells on the surface of the lower chambers decreased by a ratio of 77.8

$\% \pm 5.2 \%$ compared with the control group $(P<0.05)$, and $83.7 \% \pm 1.7 \%(P<0.05)$ in the matrigel transwell assay at the dose of $10 \mu \mathrm{M}$. All these results demonstrated that BBM could inhibit the migration and invasion of A549 cells.

\section{BBM disrupted c-Maf, PI3K/Akt and MDM2-p53 signaling pathways in A549 cells}

Since the PI3K/Akt and MDM2-P53 signal pathways were associated with proliferation, carcinogenesis and apoptosis of cells, we suppose that BBM plays an anticancer role on A549 cells through PI3K/Akt and MDM2-p53 signaling pathways. To verify this hypothesis, we detect the expressions of PI3K, MDM2, p-Akt, Akt, p53, caspase-3, c-Maf, Bcl-2 and Bax by western blotting assay. As shown in the results, BBM significantly inhibited the expressions of PI3K (Figure.4, A and C), MDM2 (Figure.4, A and D), p-Akt/Akt (Figure.4, A and E) and c-Maf (Figure.4, A and G) at the concentration of $10 \mu \mathrm{M}$, the inhibition ratio was about $36.7 \% \pm 4.3 \%(P<0.001), 13.6 \% \pm 4.1 \%(P<0.05), 20.2 \% \pm 4.2 \%(P<0.01)$ and $49.1 \% \pm 4.3 \%$ $(P<0.01)$ respectively compared to the Ctrl group. The expression of $\mathrm{Bcl}-2 / \mathrm{Bax}$ (Figure.4, $\mathrm{A}$ and $\mathrm{H}$ ) was significantly reduced by BBM $(20 \mu \mathrm{M})$ and the ratio was $28.2 \% \pm 1.6 \%$ less than the Ctrl group $(P<0.05)$. However, the expressions of p53 (Figure.4, A and F) and cleaved-caspase-3/caspase-3 (Figure.4, B and I) were increased, the rising percentage of p53 was about $33.9 \% \pm 13.1 \%$ compared to the Ctrl group $(P<0.05)$ at the dose of $10 \mu \mathrm{M}$, and cleaved-caspase-3/caspase- 3 was about $159.3 \% \pm 59.5 \%$ compared to the Ctrl group $(P<0.05)$ at the dose of $40 \mu \mathrm{M}$. 
To detect the effect of BBM on NSCLC in vivo, nude mice were used. As shown in the results, the body weight of the experimental group mice showed no significant difference compared with the Ctrl group (Figure.5 A-C). The tumor volume of the mice was significantly shrunk when the mice were treated with BBM. At the end of the study, the tumor volume reduced by $20 \% \pm 1.4 \%$ compared with the control group at the dose of $20 \mathrm{mg} / \mathrm{kg}(P<0.05$, Figure.5 A, D and F). All the animals were sacrificed the end of study. The tumor weight of the experimental group $(40 \mathrm{mg} / \mathrm{kg}$ ) was significantly decreased by a ratio of $65.1 \%$ $\pm 13.6 \%(P<0.05$, Figure. $5 \mathrm{~J})$. And weight of lungs in the BBM group $(20 \mathrm{mg} / \mathrm{kg})$ was significantly decreased compared to the Ctrl group $(P<0.05$, Figure. $5 \mathrm{H})$, weight of lung was $0.223 \pm 0.004 \mathrm{~g} /$ mice in the Ctrl group, while weight of lung in the BBM group $(20 \mathrm{mg} / \mathrm{kg})$ was $0.191 \pm 0.007 \mathrm{~g} / \mathrm{mice}$. The number of nodules per lung in the BBM group was significantly decreased compared to the Ctrl group $(P<0.001$, Figure.5, E and G). The internal organs were stripped and observed for histopathological assessment. As shown in the results, the architecture of lungs, livers, hearts and kidneys showed no difference (Figure.5 I).

\section{BBM disrupted c-Maf, PI3K/Akt and MDM2-p53 signaling pathway in vivo}

The MDM2 is an oncogene associated with various malignancies, its overexpression is vital for aggressive metastasis. We suppose that BBM plays an anticancer role in vivo through PI3K/Akt and MDM2-p53 signaling pathways. To verify this hypothesis, we detected the expressions of PI3K, p-Akt, Akt, MDM2, p53, caspase-3, c-Maf, Bcl-2 and Bax using western blot assay. As shown in the results, BBM significantly inhibited the expression of PI3K (Figure.6, A and C, P[0.01), MDM2 (Figure.6, A and D, $P \square$ 0.05), p-Akt/Akt (Figure.6, A and E, P[0.001) and c-Maf (Figure.6, A and G, P[0.01) at the dose of 20 $\mathrm{mg} / \mathrm{kg}$, the inhibition ratios were $25.2 \% \pm 3.1 \%, 32.1 \% \pm 7.7 \%, 39.1 \% \pm 5.9 \%$ and $65.3 \% \pm 7.3 \%$ respectively, and BBM significantly decreased the expression of $\mathrm{Bcl}-2 / \mathrm{Bax}$ (Figure.6, $\mathrm{A}$ and $\mathrm{H}, \mathrm{P}[0.01$ ) at the dose of $40 \mathrm{mg} / \mathrm{kg}$, the inhibition ratios was $51.5 \% \pm 3.6 \%$. While the expression of p53 (Figure.6, A and $\mathrm{F}$ ) and cleaved-caspase-3/caspase-3 (Figure.6, B and I) were increased, the rising percentage of p53 was $86.6 \% \pm 21.1 \%$ compared to the Ctrl group ( $P[0.01)$, and cleaved-caspase-3/caspase-3 was about $108.2 \% \pm 28.2 \%(P[0.01)$ at the dose of $40 \mathrm{mg} / \mathrm{kg}$.

\section{Discussion}

About 18.1 million new cancer cases were diagnosed and 9.6 million deaths from cancer in 2018 according to GLOBOCAN estimates ${ }^{[13]}$. Lung cancer is the leading cause of cancer-associated death among both men and women. In recent years, with the gradual elucidation of the molecular mechanism of NSCLC, increasingly more molecular-targeted drugs have been applied in clinical practice and achieved satisfactory results $[17,18]$. Therefore, designing drugs based on the key target genes or proteins of NSCLC is important for the treatment of NSCLC in the future.

Previous studies have demonstrated that the antitumor effects of BBM in a variety of tumors, including breast cancer[19], myeloma[7, 20], hepatoma[9, 21], prostatic neoplasms[9], pancreatic carcinoma[22] and lung cancer[23]. Jin[22] confirmed that BBM significantly downregulated the expression of the antiapoptotic proteins such as $\mathrm{Bcl}-2$ and $\mathrm{Bcl}-\mathrm{xL}$ and inhibited proliferation in pancreatic carcinoma cells. 
Du[24] found that BBM induced cell apoptosis and inhibited the cell proliferation through the PI3K/Akt pathway in lymphoma, the expressions of PI3K and p-Akt/Akt were down-regulated. Zhao[8] proved that BBM inhibited the activity of prostate cancer cells and could destroy the mitochondria of cells. All these researches indicated that the potential of BBM for cancer treatment. Thus, the primary objective of this study was to evaluate the effect of BBM on the proliferation, apoptosis, invasion and migration of human lung cancer cell line A549 cells.

$\mathrm{PI} 3 \mathrm{~K} /$ Akt pathway is an important biological mechanism in various cancers, and this pathway is associated with cell survival, invasion and migration[25]. The PI3K pathway is active in $50 \%-70 \%$ of NSCLC[14]. The phosphorylation of Akt can further phosphorylate the downstream effectors, such as mTOR and MDM2, which are closely associated with the apoptosis process[26]. Our results found that BBM could inhibit cell proliferation and induce apoptosis in vitro, and could shrink the tumor volume in vivo, and the expression of PI3K and p-Akt/Akt were also downregulated both in vitro and in vivo, which confirmed the inhibitory effect of BBM on A549 cells. MDM2 is an oncogene that is best characterized by its dynamic negative regulation of p53[15], and p53 is a tumor suppressor gene. MDM2 is often found to be high-expressed in a variety of human cancers and could promote cancer cell proliferation[27, 28]. Chen found that the expression of MDM2 was increased in lung cancer[28]. And MDM2-p53 pathway is important in regulating cell events, which can inhibit the activity by de-phospophoyrlation of PI3P[28]. Moreover, studies found that MDM2 may suppress the migration of cancer cells and could induce apoptosis[27, 29, 30]. Our results found that BBM inhibited the migration and invasion of A549 cells in vitro, and the number of nodules on lungs was significantly reduced in vivo, and the expression of MDM2 was downregulated both in vitro and in vivo. All these indicate that BBM has the ability to inhibit cancer cell metastasis. And this effect may be achieved by modulating the expression of MDM2. Recently studies found that c-Maf is overexpressed in variety of cancers including NSCLC[31], and c-Maf can promote the production of IL-10 via a pathway involving PI3K and mTOR[32]. Thus, c-Maf is thought to be a crucial molecular checkpoint that controls the immune suppression in cancer. Studies showed that cMaf is a downstream gene of $\mathrm{PI} 3 \mathrm{~K}[32]$, and is indirectly associated with cell migration[33]. Our results showed that the expressions of PI3K and c-Maf were reduced by BBM both in vitro and in vivo. Thus, the inhibition mechanism of BBM on A549 cells may be regulating the expression of c-Maf through regulating PI3K. Jianlin Zhang found that CMIP (C-Maf-inducing protein) konck-down was revealed to downregulate the expression of MDM2[34], and MDM2 has been shown to be closely associated with tumor metastasis and apoptosis. In addition, researches on the relationship between c-Maf and lung cancer were relatively few, and there was no research about BBM on the expression of c-Maf, so we detected the expression of c-Maf in vitro and in vivo. Our results revealed that the migration and invasion were inhibited by BBM both in vitro and in vivo, apoptosis was induced by BBM in vitro. The expressions of c-Maf and MDM2 were downregulated. And the expressions of p53 and cleaved-caspase-3/caspase-3 were upregulated. All these proved that BBM could inhibit the migration and induce apoptosis of A549 cells. The expression of MDM2 may be regulated by c-Maf, and p53 may be regulated by MDM2.

\section{Conclusion}


Our study demonstrated that BBM could suppress the progression of human lung cancer A549 cells, this effect may be regulating the expression of c-Maf through blocking the PI3K/Akt signaling pathway. And the MDM2-p53 signaling pathway may be regulated by c-Maf.

\section{Abbreviations}

BBM berbamine

MDM2 murine double minute 2

PI3K phosphatidylinositol 3-kinase

NSCLC non-small cell lung carcinoma

CMIP C-Maf-inducing protein

\section{Declarations}

\section{Ethics approval and consent to participate}

The studies were performed with the approval of ARRIVE Guidelines (Animal Research: Reporting of in Vivo Experiments) and approved by the Animal Care and Use Committee of Soochow University.

\section{Consent for publication}

All authors agree to publish this data.

\section{Availability of data and materials}

All data generated or analysed during this study are included in this published article.

\section{Competing interests}

The authors declare no conflict of interest.

\section{Authors' contributions}

Zhiying and Lili Liu Xu contributed to the design and implementation of experiments. Binbin Yu contributed to the statistical analysis. Li Tao contributed to the implementation of experiments. Ying Cao contributed to the design of experiments.

\section{Funding}

This work is funded by grants from the "Science and Technology Project" of Zhangjiagang (ZKF 1638), "Clinical Medical Science and Technology Development Fund Project" of Jiangsu University (JLY 
2016118), "The Integrated Traditional Chinese and Western Medicine Research Fund" of Suzhou (SYSD 2016 173) and "The science and technology development plan" from Suzhou (SYSD 2019165).

\section{Acknowledgements}

I'd like to take this opportunity to show my sincere gratitude to my colleague, Ms. Di Li, who has given me so much useful advices on my writing.

\section{References}

1. Wang S, Long S, Xiao S, Wu W, Hann SS. Decoction of chinese herbal medicine fuzheng kang-ai induces lung cancer cell apoptosis via stat $3 / \mathrm{bcl}-2 /$ caspase-3 pathway. Evidence-based complementary and alternative medicine: eCAM 2018;2018:8567905.

2. Chen B, Shen Z, Wu D, Xie X, Xu X, Lv L, Dai H, Chen J, Gan X. Glutathione peroxidase 1 promotes nsclc resistance to cisplatin via ros-induced activation of pi3k/akt pathway. BioMed research international 2019;2019:7640547.

3. Zhao Y, Tan Y, Wu G, Liu L, Wang Y, Luo Y, Shi J, Huang H. Berbamine overcomes imatinib-induced neutropenia and permits cytogenetic responses in chinese patients with chronic-phase chronic myeloid leukemia. Int J Hematol. 2011;94:156-62.

4. Jia XJ, Li X, Wang F, Liu HQ, Zhang DJ, Chen Y. Berbamine exerts anti-inflammatory effects via inhibition of nf-kappab and mapk signaling pathways. Cellular physiology biochemistry: international journal of experimental cellular physiology biochemistry pharmacology. 2017;41:230718.

5. Zhang CM, Gao L, Zheng YJ, Yang HT. Berbamine protects the heart from ischemia/reperfusion injury by maintaining cytosolic $\mathrm{ca}(2+)$ homeostasis and preventing calpain activation. Circulation journal: official journal of the Japanese Circulation Society. 2012;76:1993-2002.

6. Zheng Y, Gu S, Li X, Tan J, Liu S, Jiang Y, Zhang C, Gao L, Yang HT. Berbamine postconditioning protects the heart from ischemia/reperfusion injury through modulation of autophagy. Cell death disease. 2017;8:e2577.

7. Liang Y, Xu RZ, Zhang L, Zhao XY. Berbamine, a novel nuclear factor kappab inhibitor, inhibits growth and induces apoptosis in human myeloma cells. Acta pharmacologica Sinica. 2009;30:1659-65.

8. Zhao Y, Lv JJ, Chen J, Jin XB, Wang MW, Su ZH, Wang LY, Zhang HY. Berbamine inhibited the growth of prostate cancer cells in vivo and in vitro via triggering intrinsic pathway of apoptosis. Prostate Cancer Prostatic Dis. 2016;19:358-66.

9. Cao Y, Cao J, Yu B, Wang S, Liu L, Tao L, Sun W. Berbamine induces smmc-7721 cell apoptosis via upregulating $\mathrm{p} 53$, downregulating survivin expression and activating mitochondria signaling pathway. Experimental therapeutic medicine. 2018;15:1894-901.

10. Wei $Y L, X u L$, Liang Y, Xu XH, Zhao XY. Berbamine exhibits potent antitumor effects on imatinibresistant cml cells in vitro and in vivo. Acta pharmacologica Sinica. 2009;30:451-7. 
11. Zhang R, Dong Y, Sun M, Wang Y, Cai C, Zeng Y, Wu Y, Zhao Q. Tumor-associated inflammatory microenvironment in non-small cell lung cancer: Correlation with fgfr1 and tlr4 expression via pi3k/akt pathway. J Cancer. 2019;10:1004-12.

12. Raasmaja A, Stenius U, Ghalali A. The water extract of juniperus communis I. Induces cell death and sensitizes cancer cells to cytostatic drugs through p53 and pi3k/akt pathways. International journal of molecular sciences 2019;20.

13. Wu DM, Zhang T, Liu YB, Deng SH, Han R, Liu T, Li J, Xu Y. The pax6-zeb2 axis promotes metastasis and cisplatin resistance in non-small cell lung cancer through pi3k/akt signaling. Cell death disease. 2019;10:349.

14. Papadimitrakopoulou V. Development of pi3k/akt/mtor pathway inhibitors and their application in personalized therapy for non-small-cell lung cancer. Journal of thoracic oncology: official publication of the International Association for the Study of Lung Cancer. 2012;7:1315-26.

15. Wei Wang JW, Xiaochun Fei W, Chen Y, Li K, Shen L. Zhu: Chd1I promotes cell cycle progression and cell motility by up-regulating mdm2 in breast cancer. Am J Transl Res. 2019;11:1581-92.

16. Berdel JKaWE. C-maf in multiple myeloma: An oncogene enhancing tumor-stroma interactions. CANCER CELL 2004:109-110.

17. Silva AP, Coelho PV, Anazetti M, Simioni PU. Targeted therapies for the treatment of non-small-cell lung cancer: Monoclonal antibodies and biological inhibitors. Human vaccines immunotherapeutics. 2017;13:843-53.

18. Testa U, Castelli G, Pelosi E. Lung cancers: Molecular characterization, clonal heterogeneity and evolution, and cancer stem cells. Cancers 2018;10.

19. Liu R, Zhang Y, Chen Y, Qi J, Ren S, Xushi MY, Yang C, Zhu H, Xiong D. A novel calmodulin antagonist o-(4-ethoxyl-butyl)-berbamine overcomes multidrug resistance in drug-resistant mcf-7/adr breast carcinoma cells. Journal of pharmaceutical sciences. 2010;99:3266-75.

20. Liang Y, He X, Li X, Zhang X, Zhang X, Zhang L, Qiu X, Zhao X, Xu R. 4-chlorbenzoyl berbamine, a novel derivative of the natural product berbamine, potently inhibits the growth of human myeloma cells by modulating the nf-kappab and jnk signalling pathways. Cancer investigation. 2016;34:496505.

21. Wang GY, Lv QH, Dong Q, Xu RZ, Dong QH. Berbamine induces fas-mediated apoptosis in human hepatocellular carcinoma hepg2 cells and inhibits its tumor growth in nude mice. Journal of Asian natural products research. 2009;11:219-28.

22. Jin $X$, Wu Y. Berbamine enhances the antineoplastic activity of gemcitabine in pancreatic cancer cells by activating transforming growth factor-beta/smad signaling. Anatomical record. 2014;297:802-9.

23. Hou ZB, Lu KJ, Wu XL, Chen C, Huang XE, Yin HT. In vitro and in vivo antitumor evaluation of berbamine for lung cancer treatment. Asian Pacific journal of cancer prevention: APJCP. 2014;15:1767-9.

24. Du HP, Shen JK, Yang M, Wang YQ, Yuan XQ, Ma QL, Jin J. 4-chlorobenzoyl berbamine induces apoptosis and $\mathrm{g} 2 / \mathrm{m}$ cell cycle arrest through the pi3k/akt and nf-kappab signal pathway in 
lymphoma cells. Oncol Rep. 2010;23:709-16.

25. Liu H, Zhao J, Fu R, Zhu C, Fan D. The ginsenoside rk3 exerts anti-esophageal cancer activity in vitro and in vivo by mediating apoptosis and autophagy through regulation of the pi3k/akt/mtor pathway. PloS one. 2019;14:e0216759.

26. Kim K-Y, Park K-I, Kim S-H, Yu S-N, Park S-G, Kim Y, Seo Y-K, Ma J-Y, Ahn S-C. Inhibition of autophagy promotes salinomycin-induced apoptosis via reactive oxygen species-mediated pi3k/akt/mtor and erk/p38 mapk-dependent signaling in human prostate cancer cells. Int J Mol Sci. 2017;18:1088.

27. Xiao Z, Wang Y, Ding H. Xpd suppresses cell proliferation and migration via mir-29a-3p-mdm2/pdgf-b axis in hcc. Cell bioscience. 2019;9:6.

28. CHEN W-PC S-R, DAI X-J, GUO A-S, CHEN H-P, LIN G-S. R.-S. LIN: Research on mir-126 in glioma targeted regulation of pten/pi3k/akt and mdm2-p53 pathways. European Review for Medical Pharmacological Sciences. 2019;23:3461-70.

29. Wang W, Hu B, Qin JJ, Cheng JW, Li X, Rajaei M, Fan J, Yang XR, Zhang R. A novel inhibitor of mdm2 oncogene blocks metastasis of hepatocellular carcinoma and overcomes chemoresistance. Genes diseases. 2019;6:419-30.

30. Liu D, Zhang J, Wu Y, Shi G, Yuan H, Lu Z, Zhu Q, Wu P, Lu C, Guo F, Chen J, Jiang K, Miao Y. Yy1 suppresses proliferation and migration of pancreatic ductal adenocarcinoma by regulating the cdkn3/mdm2/p53/p21 signaling pathway. International journal of cancer. 2018;142:1392-404.

31. Liu M, Tong Z, Ding C, Luo F, Wu S, Wu C, Albeituni S, He L, Hu X, Tieri D, Rouchka EC, Hamada M, Takahashi S, Gibb AA, Kloecker G, Zhang HG, Bousamra M, Hill BG, Zhang X, Yan J. Transcription factor c-maf is a checkpoint that programs macrophages in lung cancer. The Journal of clinical investigation 2020.

32. van den Bosch MW, Palsson-Mcdermott E, Johnson DS, O'Neill LA. Lps induces the degradation of programmed cell death protein 4 (pdcd4) to release twist2, activating c-maf transcription to promote interleukin-10 production. J Biol Chem. 2014;289:22980-90.

33. Xie Q, McGreal R, Harris R, Gao CY, Liu W, Reneker LW, Musil LS, Cvekl A. Regulation of c-maf and alphaa-crystallin in ocular lens by fibroblast growth factor signaling. J Biol Chem. 2016;291:394758.

34. Zhang J, Huang J, Wang X, Chen W, Tang Q, Fang M, Qian Y. Cmip is oncogenic in human gastric cancer cells. Mol Med Rep. 2017;16:7277-86.

\section{Figures}



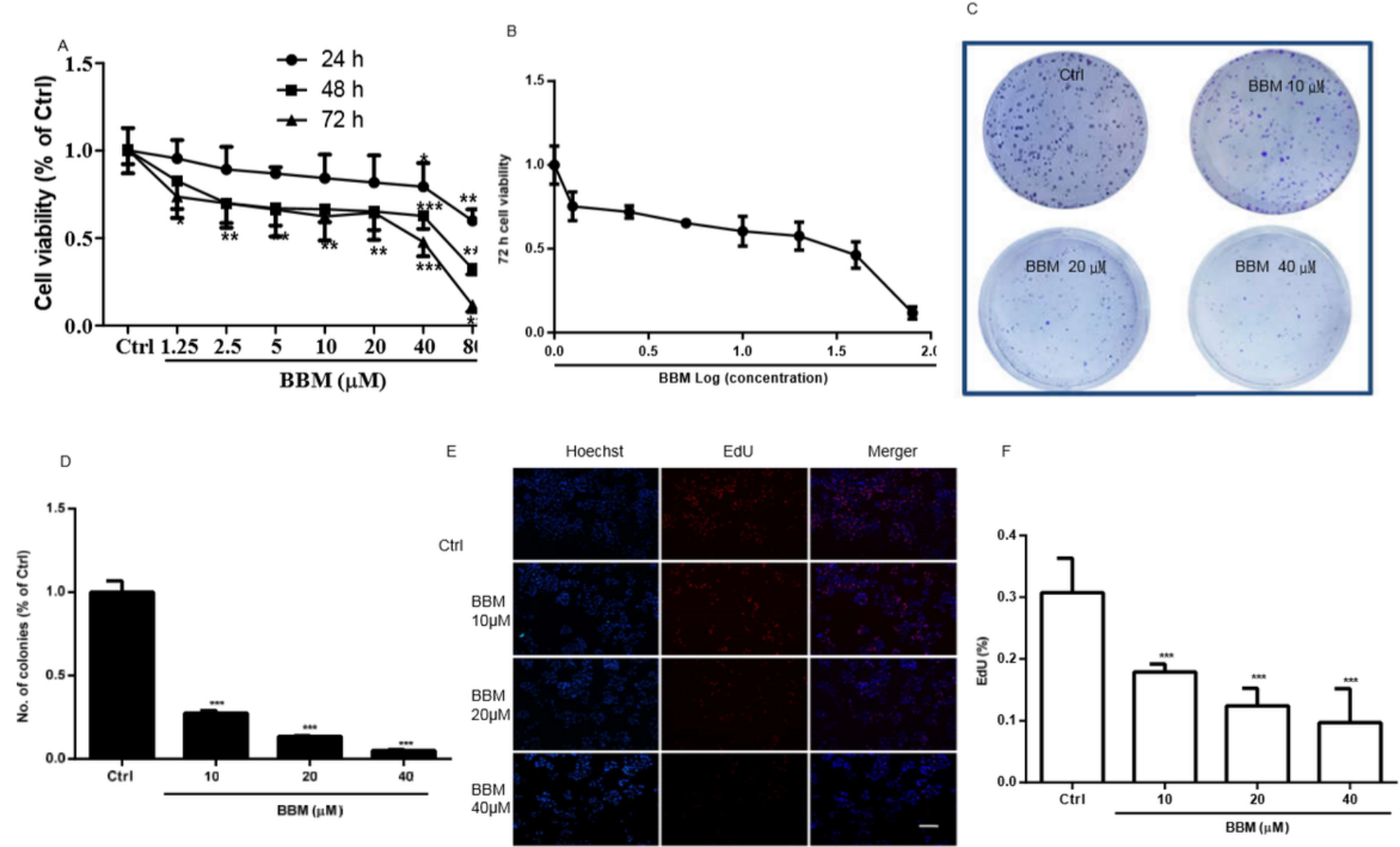

\section{Figure 1}

Effect of BBM on the cell viability and proliferation of A549 cells. Cells were treated with vehicle or applied concentrations of BBM, MTT assay (A-B), colony formation assay ( $C$ and D, medium was renewed every 3 days) and EdU assay (E and F, Bar $\$ 100 \mu \mathrm{m}$ ) were executed. Date were expressed as mean \pm SD ( $\mathrm{n}$ $\otimes 3) .{ }^{*} P<0.05, \star \star P<0.01,{ }^{\star} \star \star * P<0.001$ vs. “Ctrl” group. 


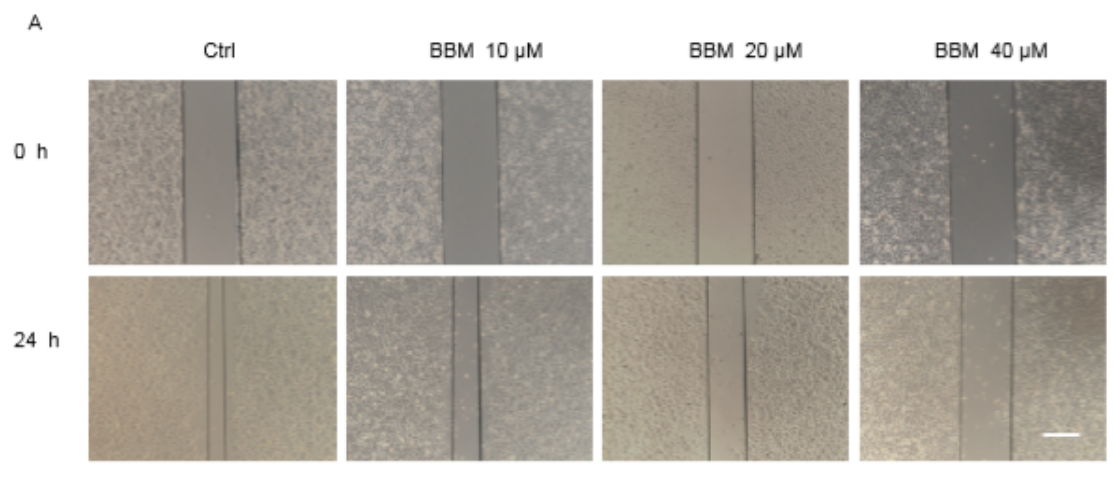

B
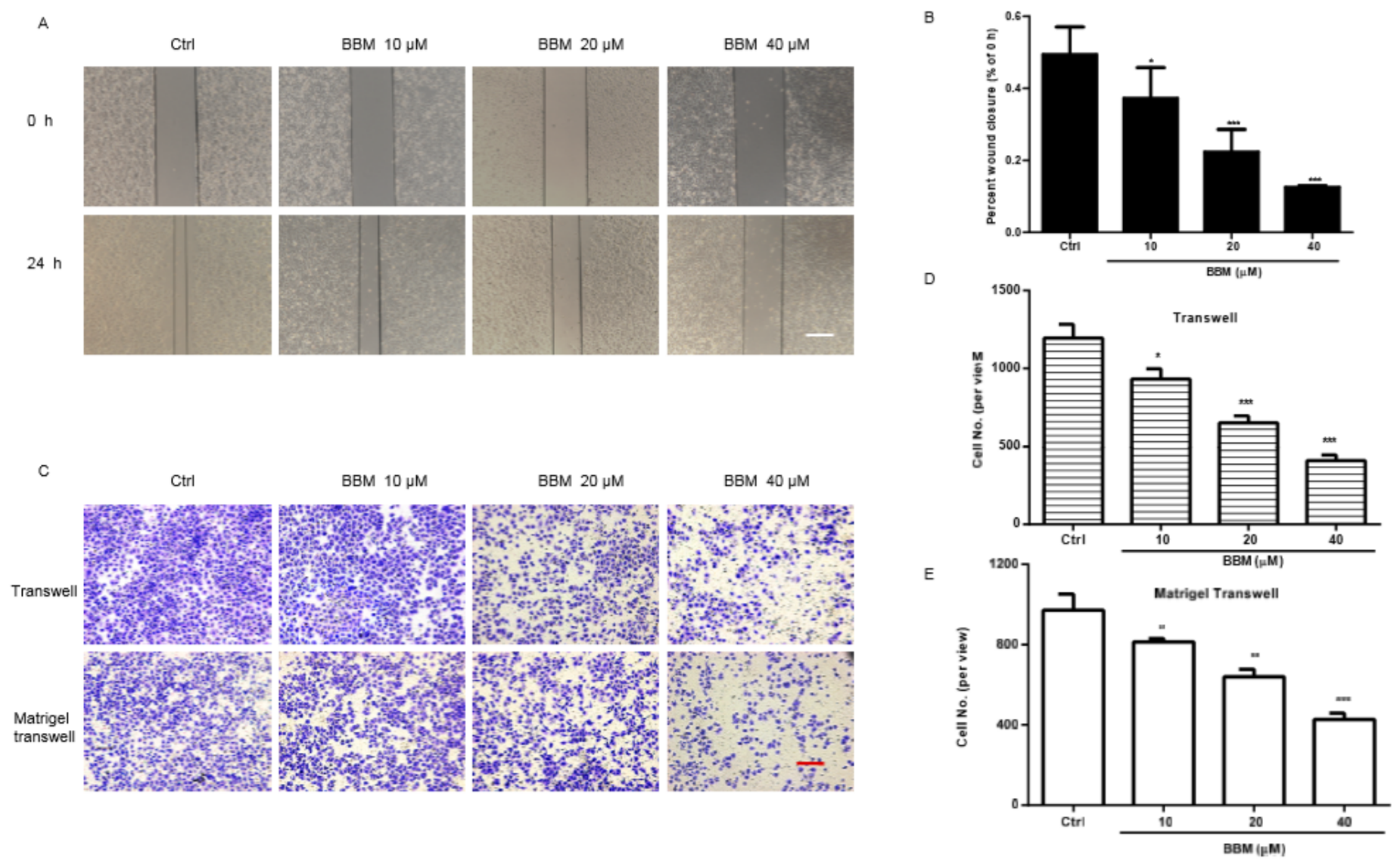

Figure 2

Effect of BBM on cell death and apoptosis of A549 cells. Cells were untreated (Ctrl) or treated with BBM, cell death and apoptosis was detected through typlan blue assay ( $A$ and $B$ ) and Cell Death Detection Elisa assay $(C)$. Date were expressed as mean $\pm S D(n \rrbracket 3)$. ${ }^{*} P<0.05,{ }^{* *} P<0.001$ vs. "Ctrl” group. 


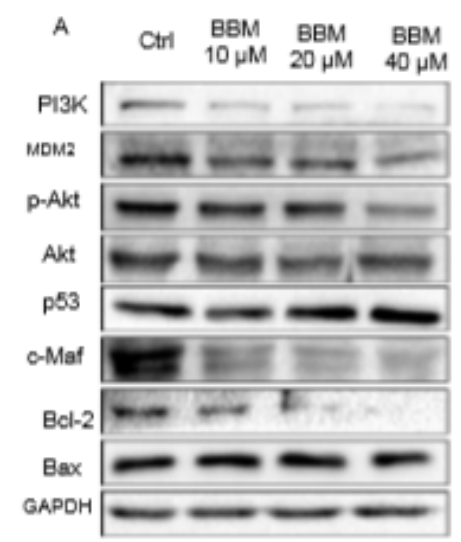

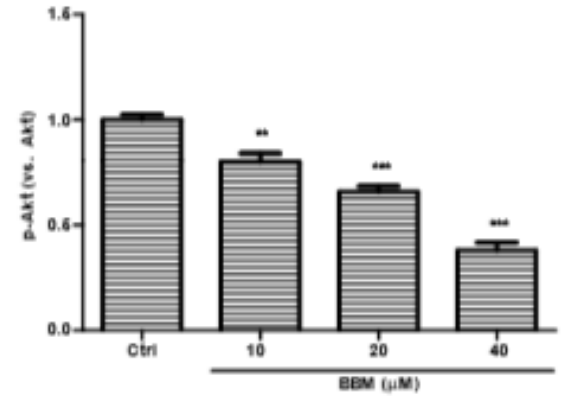

B
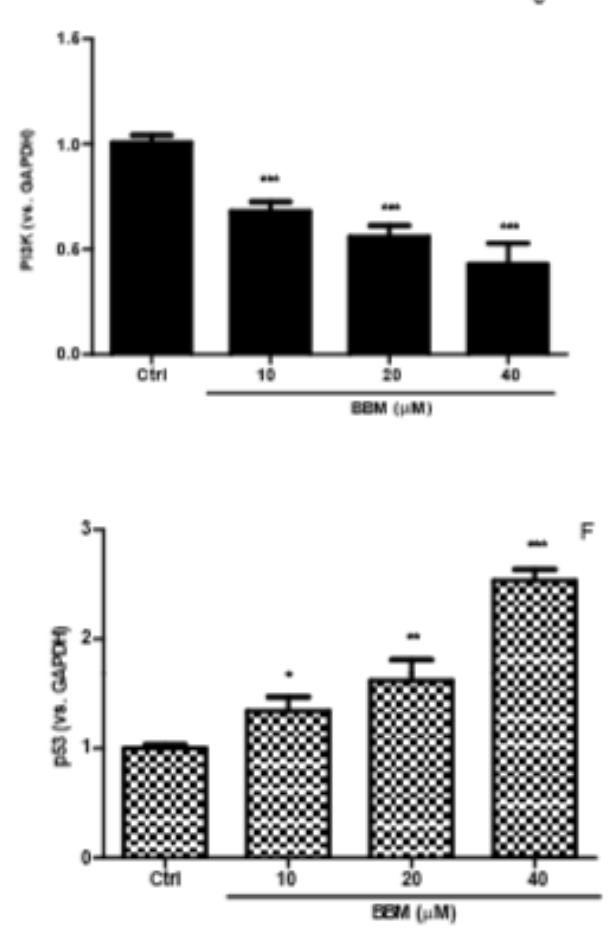
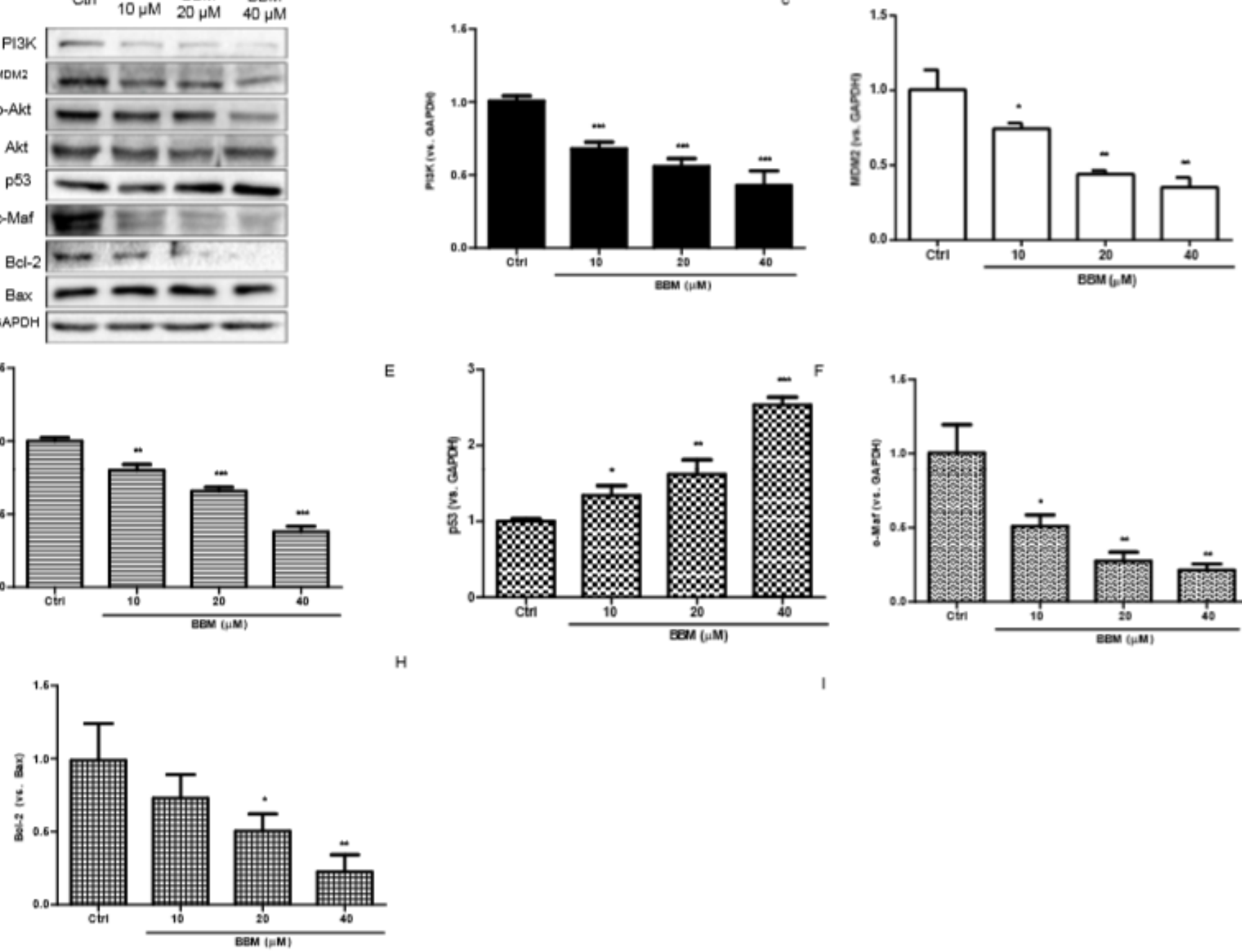

Figure 3

Effect of BBM on the migration and invasion of A549 cells in vitro. Cells were treated with vehicle of different concentrations of BBM, cell migration and invasion was tested by wound scratch assay ( $A$ and $B, B a r \otimes 100 \mu \mathrm{m})$, transwell assay ( $C$ and $D, B a r \otimes 100 \mu \mathrm{m})$ and matrigel transwell assay ( $C$ and $E$ ). Date were expressed as mean $\pm \mathrm{SD}(\mathrm{n} \rrbracket 3)$. ${ }^{\star} \mathrm{P}<0.05,{ }^{\star} * \mathrm{P}<0.01,{ }^{\star \star \star} \mathrm{P}<0.001$ vs. “Ctrl” group. 


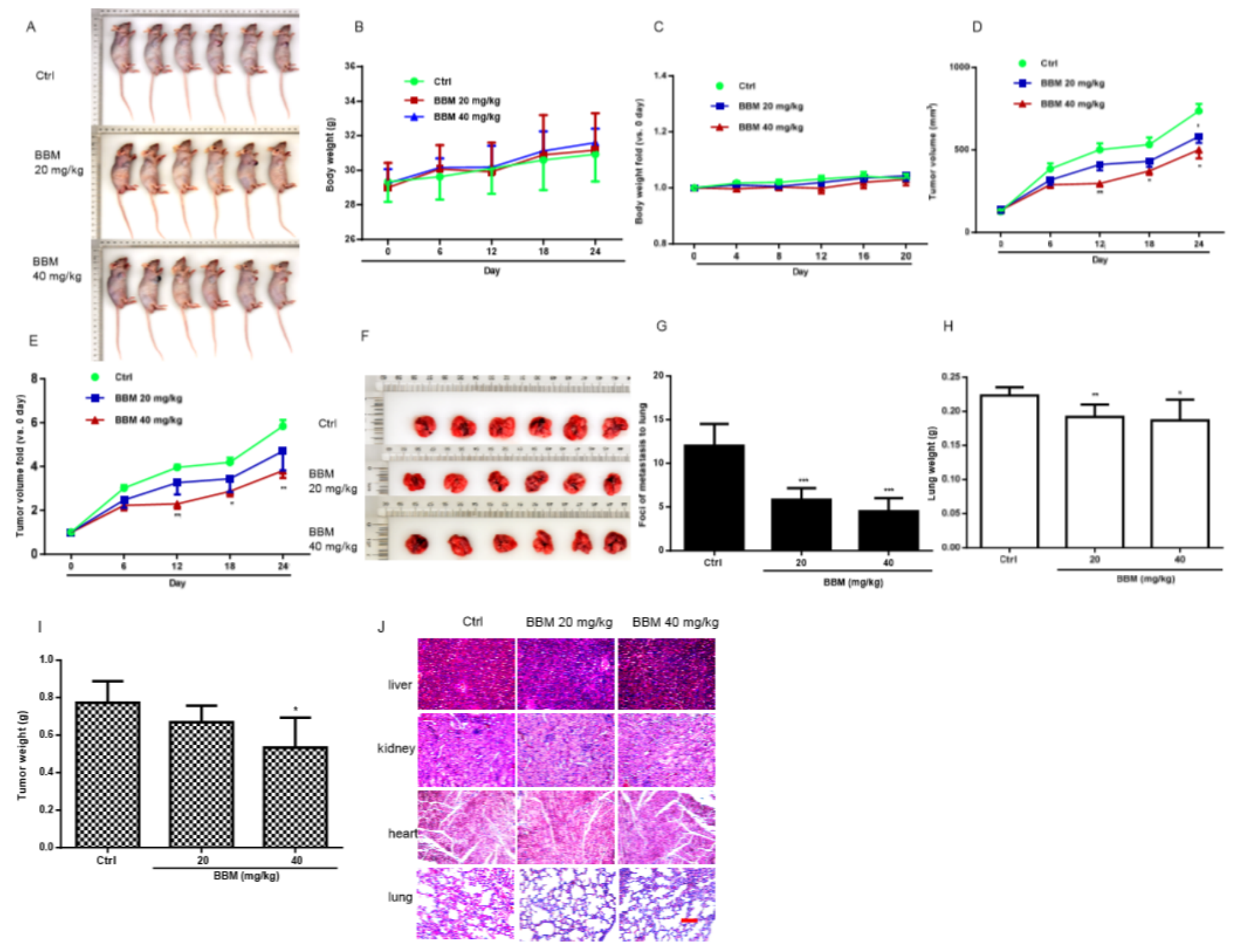

Figure 4

Effect of BBM on PI3K/Akt and MDM2/p53 signal pathways in A549 cell. Cells were untreated (Ctrl) or treated with BBM, the expression of PI3K ( $A$ and C), MDM2 (A and D), p-AKT/AKT ( $A$ and E), p53 ( $A$ and F), c-Maf ( $A$ and $G), B c l-2 / B a x(A$ and $H)$ and Cleaved-caspase-3/caspase-3 (B and I) were tested by western blot. Date were expressed as mean $\pm S D(n \varangle 3)$. ${ }^{*} P<0.05$, ${ }^{\star \star} P<0.01,{ }^{\star \star \star} P<<0.001$ vs. "Ctrl” group. 

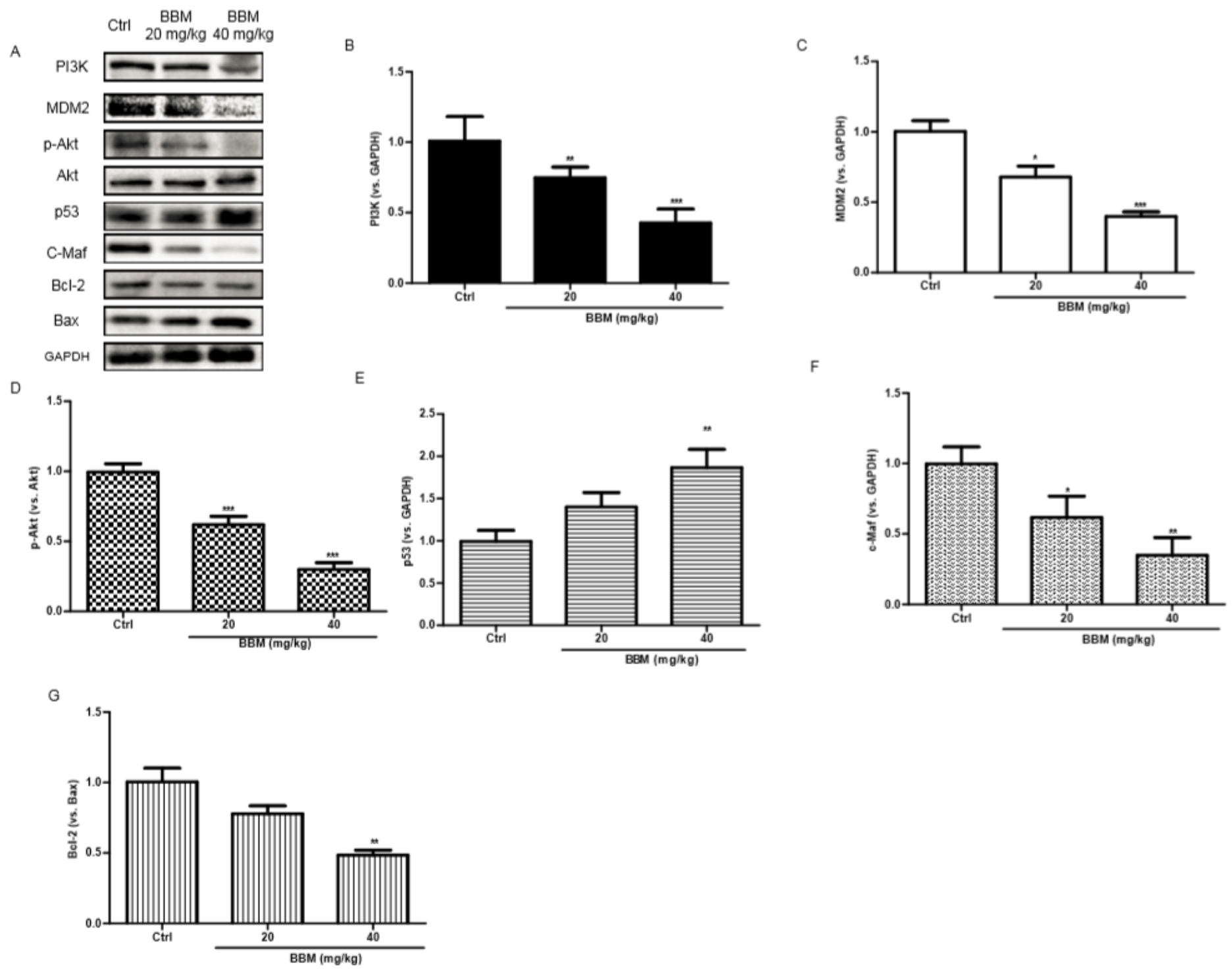

Figure 5

Effect of BBM on the tumor growth and metastasis in vivo. The nude mice were implanted with A549 cells. When the tumor reached $150 \mathrm{~mm}$, the mice were treated with vehicle (Ctrl group) or BBM (A). The body weight of the mice ( $B$ and $C$ ) and the tumor volume ( $D$ and $E$ ) were record. The foci of metastasis to lung $(F$ and $G$ ), lung weight $(H)$ and tumor weight $(I)$ were measured. The histopathological changes of liver, kidney, heart and lung were stained with hematoxylin/eosin and photographed (J, Bar冈100 $\mu \mathrm{m})$. Date were expressed as mean $\pm S D(n \varangle 6)$. ${ }^{\star} P<0.05$, ${ }^{\star \star} P<0.01$, ${ }^{\star \star *} P<0.001$ vs. "Ctrl” group. 


\section{Image not available with this version}

\section{Figure 6}

Effect of BBM on PI3K/Akt and MDM2/p53 signal pathways in tumor lysis. BALB/c mice were untreated (Ctrl) or treated with $B B M$, the animal were sacrificed and the tumor were used for western assay. The expression of PI3K (A and C), MDM2 (A and D), p-Akt/Akt ( $A$ and E), p53 (A and F), c-Maf ( $A$ and G), Bcl2/Bax $(A$ and $H)$ and Cleaved-caspase-3/caspase-3 ( $B$ and $I)$ were tested by western blot. ${ }^{*} P<0.05$, ${ }^{* \star} P<$ $0.01, \star \star \star P<0.001$ vs. "Ctrl” group. 